\title{
Role of Procurement Management on the Performance of Constituencies' Development Fund Projects in Kenya: A Case Study of Kiambu County
}

\author{
Olympia Muhanga Musonye ${ }^{1}$, Patrick Mwangangi ${ }^{2}$ \\ ${ }^{1}$ Jomo Kenyatta University of Agriculture and Technology, School of Business Management \\ ${ }^{2}$ Jomo Kenyatta University of Agriculture and Technology, School of Business Management
}

\begin{abstract}
In this paper, we present results of a study which examined the effects of various tools of procurement management on the performance of Constituencies Development Fund projects in the 12 Constituencies in Kiambu County in Kenya. The tools evaluated included Sustainable purchasing, Information and communication Technology, Contract process and Supplier relationship. A regression model was used to test the relationship. Ninety six out of 720 employees of Constituency Devleopment Funds' offices from the 12 constituencies of Kiambu County were tested using questionnaires. The results showed that there exists, on a linkerd scale of 1-5, a relationship between the tools and project performance.The results of the analysis show that performance on procurement management techniques are related to the project performance by various coefficient values and a constant of 3.974, with an error term of 0.2325 . The model, however, does not closely represent the real points of the data, with a coefficient of determination of 0.098 .
\end{abstract}

Keywords - Information and communication Technology, Contract process, Procurement management, Project Performance, Supplier relationship, Sustainable purchasing.

\section{Introduction}

Procurement forms the critical link between the government expenditure management and the attainment of the social and objective goals. Poor procurement planning, outdated policies and regulations and poor contract administration lead to inefficient procurement process, hence distorting resource allocation [1]. The inefficiencies are manifested through unnecessary costs, project delays, poor service delivery and failed implementation of government plans [2]. Constituencies Development Fund (CDF) came to exist through the Constituencies Development Fund Act; 2003. The primary objective of the CDF was to address poverty at grassroots level. The CDF carries out different projects across the country in order to achieve its objective. Performance of Procurement processes is part of the elements that determine the success and viability of the CDF projects [3].

The role of the Performance on Procurement Management in the Constituencies Development Fund projects has been in public limelight, with stakeholders seeking to understand how this function of management can be useful in project performances [4]. Studies have been carried out before, in different jurisdictions, attempting to understand various aspects of supply chain management function in projects. One such a study was carried out to analyze the purchasing process for green consumers in relation to consumer technology products in the UK. Data were collected from 81 self-declared green consumers through in depth interviews on recent purchases of technology products. A green consumer purchasing model and success criteria for closing the gap between green consumers' values and their behavior were developed. The paper concluded that incentives and single issue labels (like the current energy rating label) would help consumers concentrate their limited efforts. More fundamentally, being green needs time and space in people's lives; however, this is not available in an increasingly busy lifestyles [5].

Another study was carried out to explore the relationships between the formal versus informal nature of opportunism and the formal versus informal nature of contractual governance. The study used a unique data set of 102 buyers-supplier disputes to explore in depth the different types of opportunism; that is, strong form versus weak form opportunism and different types of contracting mechanisms; that is, the controlling and coordinating functions of formal contracts and the cooperative and competitive sides of relational contracts. From the detailed empirical analysis, there was found a distinct relationship between the different contracting mechanisms, the different types of opportunism, and the level of legal fees necessary to deal with the dispute [6].

An in-depth longitudinal study of the alliance contracting process in the animated film industry was carried out. The study analyzed an organizational learning perspective on the contracting process. First, the study's findings suggest that during the contracting process, firms can learn about the way to deal with the contracting process, about themselves and their partner, and about the transaction features. Second, the case 
analysis indicates a combination of experiential, vicarious and inferential learning mechanisms. The findings show that the drafting of contractual clauses fosters learning and, in turn, this learning triggers new contractual negotiations. Hence the study concludes that the alignment between transaction features and the choice of contractual governance results from learning during the contracting process [7].

The studies carried out are of essence in understanding various aspects of supply chain management, but they are not conclusive as to provide solutions to the question of the role of supply chain management in project performance. The studies were also done in different countries that have different economic and political environment from Kenya. Some of the studies do not give a basis for statistical generalization as they look into the performance of procurement management as a general concept. Some of the findings are likewise not enough to provide statistics that are needed to understand the role of performance on procurement management in a project as the findings were done based on a broader range of management issues. Whereas the findings provide invaluable literature which can be used in understanding, the role of performance on procurement management in projects, the information cannot be as valuable as that generated when a study is done solely on the role of performance on the procurement management in CDF projects.

\section{Methods}

This study used descriptive survey design. The study gathered data in order to describe events and issues in a typical way. The statistic was organized, tabulated, depicted and described by use of visual aids. The population for this study was the Constituencies Development Fund projects in Kiambu County. The target population of the study was 720 employees of the CDF offices in the constituencies' offices in Kiambu County. Of these, 120 were from the Constituency Development Fund Committee (CDFC) and 600 Procurement Management Committee (PMC). The target population was essential for the study as the CDFC and PMC play a major role in the procurement management of the CDF projects. In addition, the committees have the mandate to monitor and evaluate the project performance within their constituencies. The sampling frame of the study was made up of CDFC and PMC members. The list of the CDFC members was obtained from the Clerk of the Kenya National Assembly. The list of the PMC members was derived from the secretaries of each of the twelve constituency offices. The unit of the observation for this study was the 36 CDFC and 60 PMC from the twelve constituencies, totaling to 96 members.

The study used closed ended questionnaires to collect data. The instrument had a five point Likert scale to measure the level of agreement or disagreement with certain assertions about use of procurement management tools and performance of projects in CDF. Quantitative techniques were used to analyze the data. The study generated the descriptive statistics after data collection, estimation of population parameters from the statistics, and make inferences based on the statistical findings. A multiple regression was used to establish the relationship between the variables (Sustainable Purchasing, Information and Communication Technology, Contracting process and Supplier Relationship) and make inferences in relation to the performance of CDF.

\section{Results And Analysis}

This study intended to find out the relationship between the performances on procurement management in CDF projects in the 12 constituencies of Kiambu County. In the analysis, the project performance indicators of timely completion of projects, quality conformance, and completion of project within budget, cost performance and customer satisfaction were used as the dependent variables. Sustainable procurement, information technology, contracting processing and Supplier relationship were used as the independent variables. They were used for measurement of project procurement management. The regression model shows that the procurement management techniques are significantly related to the project performance by various coefficient values and a constant of 2.878 , with an error term of 0.3723 . The model, however, does not closely represent the real points of the data, with a coefficient of determination of 0.189 . The regression model is statistically significant at a $95 \%$ confidence level.

It was identified that the use of sustainable procurement had an influence on the performance of CDF projects in Kiambu County. From the regression model, it was ascertained that use of sustainable procurement had a positive effect on the performance of CDF projects in Kiambu County. The use of sustainable procurement methods is related to $\mathrm{CDF}$ project performance by -0.31023 . The use of information technology tools was ranked to be a useful contributor to CDF project performance in Kiambu County. According to the regression model, this variable is positively related to project performance with a coefficient of 0.63239 . Electronic Fund Transfer was ranked to have the highest effect on project performance followed by the availability of computers in the offices of procurement procedures. This is followed by the use of purchase to pay system. ICT skills of the PMC and the CDFC employees and E-purchasing was ranked second last and last respectively.

Contracting process was also found to be related to the performance of CDF projects in Kiambu County. Contracting processing was found to be strong and positively related to the performance of projects. 
The two are related by 0.77004 . According to the regression model, there is a direct relationship between employment of the procurement contracting and project performances. In the analysis, it was found that supplier relationship was one of the determinants of CDF project performance in Kiambu County. According to the regression model, this variable is positively related to project performance with a coefficient of 0.4076 . The average score for the influence of supplier relationship on the CDF project performance was 3.33. Supplier development had the highest score (3.42) among all the variables of the supplier relationship. The lowest score (3.26) was attained by information sharing and supplier access to information variable.

\section{Conclusion And Recommendations}

From the results presented in this section, it is concluded that performance on procurement management does indeed affect the performance of CDF projects in Kiambu County. There is a correlation between the procurement management tools ${ }^{\text {ee }}$ use and the project performance. The results are in agreement with the findings of other studies carried out relating performance on procurement management and project performance. For instance, a study carried out by [8] confirmed that purchasing decisions had a significant effect on the performance of projects. Findings by [9] also support the results of this study. The authors suggested that cooperative procurement procedures like joint specification, selected tendering, soft parameters in bid evaluation, joint subcontractor selection, incentive-based payment, collaborative tools, and contractor self-control generally have a positive influence on project performance. However, they asserted that these relationships are moderated or mediated by the collaborative climate in the project and moderated by the overall project characteristics. The research therefore concludes that there is a relationship between procurement management and CDF project performance in Kiambu County. These findings can be used to improve the performance of various projects initiated in the country.

Even though the study has been exhaustive in achieving its objectives, there are areas of improvement that could be adopted. There are some limitations to this study. The explanation to the relationship between some of the procurement management variables and project performances is not exhaustive. As well, the answers given by the respondents could be subjective. These studies recommend a similar study to be extended to other counties where CDF and PMG projects are being implemented so as to validate their outcome with these findings. Additionally, other studies to add the variables and compare with the studies variable and make a consensus prudent decision from the findings.

\section{References}

[1] Alwaer, H., \& Clements-Croome, D. J. (2010). Key performance indicators (KPIs) and priority setting in using the multi-attribute approach for assessing sustainable intelligent buildings. Building and Environment, 45(4), 799-807.

[2] Preuss, L. (2009). Addressing sustainable development through public procurement: the case of local government. Supply Chain Management: An International Journal, 14(3), 213-223.

[3] Kinyua, M., \& Ogollah, K. O. (2013). Influence of procurement process on performance of Constituency Development Fund projects in Marakwet East Constituency in Kenya. International Journal of Social Sciences and Entrepreneurship, 1(7), 90-103.

[4] Poister, T. H. (2008). Measuring performance in public and nonprofit organizations. John Wiley \& Sons.

[5] Miemczyk, J., Johnsen, T. E., \& Macquet, M. (2012). Sustainable purchasing and supply management: a structured literature review of definitions and measures at the dyad, chain and network levels. Supply Chain Management: An International Journal, 17(5), 478496.

[6] Lumineau, F., \& Malhotra, D. (2011). Shadow of the contract: How contract structure shapes interfirm dispute resolution. Strategic Management Journal, 32(5), 532-555.

[7] Masterman, J. (2003). An introduction to building procurement systems. Routledge.

[8] Schiele, H., Veldman, J., \& Hüttinger, L. (2011). Supplier innovativeness and supplier pricing: The role of preferred customer status. International Journal of Innovation Management, 15(01), 1-27.

[9] Eriksson, P. E., \& Westerberg, M. (2011). Effects of cooperative procurement procedures on construction project performance: a conceptual framework. International Journal of Project Management, 29(2), 197-208. 